Contacts

Publisher: Ben Crowe

Editor: Paul Smaglik

Marketing Manager: David Bowen

European Head Office,

London

The Macmillan Building

4 Crinan Street

London N1 9XW, UK

Tel +44 (0) 2078434961

Fax +44 (0) 2078434996

e-mail: naturejobs@nature.com

Naturejobs Sales Director

Nevin Bayoumi (4978)

UK/ RoW/ Ireland:

Matt Powell (4953)

Andy Douglas (4975)

Frank Phelan (4944)

Scandinavia/ Spain/ Portugal:

Evelina Rubio Håkansson (4973)

Natureevents: Sille Opstrup (4994)

France/ Switzerland:

Amelie Pequignot (4974)

Production Manager: Billie Franklin

To send materials use London

address above.

Tel +44 (0) 2078434814

Fax +44 (0) 2078434996

e-mail: naturejobs@nature.com

Naturejobs web development

Tom Hancock

Naturejobs online production:

Stefan Hales

European Satellite Office

Germany/ Austria/ Italy/

The Netherlands/ Belgium

Patrick Phelan, Odo Wulffen

Tel + $498954905711 /-2$

$\mathrm{Fax}+498954905720$

e-mail: p.phelan@nature.com

o.wulffen@nature.com

US Head Office, New York

345 Park Avenue South,

10th Floor, New York, NY 10010-1707

Tel +1 8009897718

Fax +18009897103

e-mail: naturejobs@natureny.com

US Sales Manager: Peter Bless

Japan Head Office, Tokyo

MG Ichigaya Building (5F),

19-1 Haraikatamachi,

Shinjuku-ku,

Tokyo 162-0841

Tel +81332678751

Fax +81332678746

Asia-Pacific Sales Director:

Rinoko Asami

e-mail: rasami@naturejpn.com

\title{
naturejobs
}

\section{The best years of our lives}

've lost count of how many times I've been told by tenured, senior researchers that doing their postdoc was the best part of their scientific life. I usually bite my tongue to stop myself from saying: "Then why don't you go back?" Senior researchers, now burdened with management and grant-writing duties, tend to remember their fellowship years as a period of pure scientific pursuit. And poverty is so much more romantic when you are no longer experiencing it.

But postdocs now are very different from the fellowships of old. Today's postdocs are feeling the squeeze. They often need to start seeking their first grant as soon as they begin their fellowship. And their long-term future is far from secure: there are far more fellows than there are tenure-track positions.

Administrators, of course, prefer ever greater competition so that they can fill the few permanent slots with the best and the brightest - the scientific equivalent of rock stars.

Sadly, not every scientist can become a rock star; there simply isn't room on the stage. So what can the scientific equivalent of the opening acts and road crew do? Some simply leave - one researcher on a fixed-term contract at the University of Birmingham, UK, quit to train as a gas fitter - whereas others seek work outside the lab (see EMBO Rep. 5, 660-662; 2004).

The present system simply doesn't offer a solution. Too few tenure-track positions and a practice of short-term contracts, especially in Europe, mean that new scientists are constantly pushed into the system, but they often don't have a destination.

Clearly, there needs to be some middle ground. A mechanism that allows experienced scientists to continue doing benchwork, if they so choose - the kind of work that tenured management looks back upon so fondly.

\section{Paul Smaglik}

Naturejobs editor

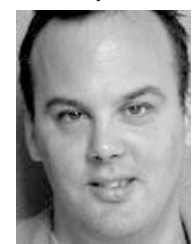

\section{Contents}

\section{WWW.NATUREJOBS.COM}

Career centre

Information on the scientific job market
FOCUS

SPOTLIGHT

RECRUITMENT

ANNOUNCEMENTS

EVENTS 